\title{
VPLIV DODATKA NANOFIBRILIRANE CELULOZE NA MEHANSKE LASTNOSTI POLI(3-HIDROKSIBUTIRATA)
}

\author{
THE IMPACT OF THE NANOFIBRILLATED-CELLULOSE \\ ADDITION ON THE MECHANICAL PROPERTIES OF \\ POLY(3-HYDROXYBUTYRATE)
}

\author{
Vesna Žepič', Erika Švara Fabjan², Ida Poljanšek ${ }^{3}$, Primož Oven ${ }^{3}$ \\ ${ }^{1}$ TECOS - Razvojni center orodjarstva Slovenije, Kidričeva 25, 3000 Celje, Slovenija \\ 2ZAG - Zavod za gradbeništvo Slovenije, Dimičeva 12, 1000 Ljubljana, Slovenija \\ ${ }^{3}$ Univerza v Ljubljani, Biotehniška fakulteta, Oddelek za lesarstvo, Jamnikarjeva 101, 1000 Ljubljana, Slovenija \\ vesna.zepic@tecos.si
}

Prejem rokopisa - received: 2016-07-15; sprejem za objavo - accepted for publication: 2016-09-20

doi:10.17222/mit.2016.192

Namen prispevka temelji na inovativnem postopku izdelave nanokompozitov na osnovi poli(3-hidroksibutirata) (PHB) in nanofibrilirane celuloze (NFC). Raziskovalno delo obravnava pripravo koncentratnih mešanic PHB-prahu in NFC v vodni raztopini za tehnologijo ekstruzijskega mešanja. Ekstrudat koncentrirane mešanice PHB/NFC je bil nato uporabljen kot dodatek h granulirani obliki PHB pri pripravi brizganih vzorcev z različnimi utežnimi deleži NFC. V prispevku so podane določene omejitve pri predelavi tovrstnih materialov in predlagane uporabne rešitve za njihovo optimiziranje. Morfološke lastnosti nanokompozitnih komponent smo raziskali z elektronsko mikroskopijo (FE-SEM), mehanske lastnosti pa z nateznim preizkusom. Morfološka preiskava koncentratnih mešanic je razkrila prepleteno sestavo celuloznih nanofibril in polimernih kroglic, pri čemer se posamezne fibrile prepletajo v obliki širših pramenov in ustvarjajo videz zamrežene strukture znotraj polimerne komponente. Mikroskopski posnetki nanokompozitnih mešanic in izboljšane mehanske lastnosti izhodnih materialov potrjujejo, da je adhezivni stik med matrično in ojačitveno komponento dosežen, porazdelitev celuloznih nanofibril po polimerni osnovi pa homogena. Nanokompoziti z visokimi utežnimi deleži NFC (10\% utežnega deleža) dosegajo pomembno večje vrednosti modula elastičnosti $\left(E_{\mathrm{t}}=1720 \mathrm{MPa}\right)$ in raztezka pri pretrgu $\left(\varepsilon_{\mathrm{b}}=3,1 \%\right)$ ter prenesejo višje pretržne napetosti $\left(\sigma_{\mathrm{M}}=26 \mathrm{MPa}\right) \mathrm{v}$ primerjavi z referenčnim polimernim vzorcem $\left(E_{\mathrm{t}}=1340 \mathrm{MPa} ; \varepsilon_{\mathrm{b}}=2,4 \% ; \sigma_{\mathrm{M}}=20 \mathrm{MPa}\right)$. Rezultati študije dokazujejo, da je ob pravilni predpripravi polimernih mešanic in optimizaciji tehnologije ekstruzijske predelave, mogoče izdelati trdne in žilave materiale, pri čemer delež ojačitvene faze narekuje stopnjo izboljšave končnih lastnosti biopolimerne osnove.

Ključne besede: nanofibrilirana celuloza, poli(3-hidroksibutirat), morfologija, mehanske lastnosti, ekstruzija, tehnologija brizganja

In this paper a novel processing route for nanocomposites, based on (3-hydroxybutyrate) (PHB) and nanofibrillated cellulose (NFC), is presented. To obtain a uniform dispersion of the reinforcing filler, a PHB powder was first dispersed in water, mixed with an NFC aqueous suspension and then freeze dried to eliminate the water phase from the ensuing system. The dried batch was then extruded and added to the granulated PHB in different weight proportions. Nanocomposites with various NFC contents were subsequently produced with the injection-moulding technology. The processing limits and feasible solutions for their optimization are thoroughly described within this work. Morphological properties were investigated with FE-SEM, while mechanical properties were determined via a tensile test. SEM images showed that the PHB powder can be effectively incorporated into the mesh of cellulose nanofibrils, as clearly evident by the interlaced structure of individual fibrils with the average lateral dimensions of $69 \pm 14 \mathrm{~nm}$. Improved mechanical properties and SEM observations confirmed a good interfacial adhesion and uniform distribution of the reinforcing component. Compared to the unfilled matrix $\left(E_{\mathrm{t}}=1340 \mathrm{MPa} ; \sigma_{\mathrm{M}}=20 \mathrm{MPa}\right.$ $\left.\varepsilon_{\mathrm{b}}=2.4 \%\right)$, an escalating trend in Young's modulus $\left(E_{\mathrm{t}}=1720 \mathrm{MPa}\right)$ and tensile strength $\left(\sigma_{\mathrm{M}}=26 \mathrm{MPa}\right)$, along with decisively improved values of the elongation at break $\left(\varepsilon_{\mathrm{b}}=3.1 \%\right)$, were observed for the nanocomposites with the highest content of NFC According to the results presented, strong and tough nanocomposites can be produced via extrusion moulding, whereby the proportion of the reinforcing phase dictates the final material performances.

Keywords: nanofibrillated cellulose, poly(3-hydroxybutyrate), morphology, mechanical properties, extrusion, injection moulding

\section{UVOD}

Sintetični polimeri so vsestransko uporabni materiali, brez katerih si naš vsakdanjik težko predstavljamo. Ena njihovih glavnih slabosti je dolgotrajen proces razgradnje, druga pa pridobivanje, ki temelji na neobnovljivih surovinskih virih. Poleg raziskav o možnostih recikliranja odpadnih plastičnih mas se $\mathrm{v}$ zadnjem času raziskave vse intenzivneje usmerjajo $\mathrm{v}$ razvoj biopolimernih materialov, ki bi zmanjšali škodljive učinke na okolje in znižali našo odvisnost od ekonomsko nestabilnih naftnih derivatov. Tržno uspešen in v svetu vedno bolj prodoren biopolimer je polimlečna ali polilaktična kislina (PLA), proizvedena s fermentacijo ogljikovih hidratov. ${ }^{1}$ Druga pomembna skupina biorazgradljivih polimerov so polihidroksialkanoati (PHA), sintetizirani preko bakterijsko vodenih fermentacijskih postopkov. ${ }^{2}$ Najbolj znana oblika PHA polimerov z nizko molsko maso je poli(3-hidroksibutirat). ${ }^{3}$ Obe skupini razgradljivih polimerov imata visok tržni potencial na področju bioplastike, vendar nekatere njihove lastnosti, kot so krhkost, nizka temperaturna odpornost, visoka paroprepustnost in nizka viskoznost za nadaljnjo predelavo, ${ }^{4}$ omejujejo njihovo 
širšo uporabo. Ena izmed rešitev za izboljšanje teh lastnosti je vgradnja nano-ojačitvenih elementov $\mathrm{z}$ ugodnim razmerjem med njihovo dolžino in premerom. Dober primer takih dodatkov so celulozne nanofibrile oz. nanofibrilirana celuloza (NFC), navadno pridobljena iz celuloze lesa, ki po fizikalnih, kemičnih in mehanskih lastnostih daleč presega lastnosti makroceluloznih vlaken. ${ }^{5}$ Modul elastičnosti celuloznih nanofibril je teoretično višji od jekla in dosega vrednosti blizu $137 \mathrm{GPa}^{6}$ Natezna trdnost NFC je približno $10 \mathrm{GPa}$, koeficient termičnega raztezka pa je nizek in dosega vrednosti blizu $2,6 \cdot 10^{-6} \mathrm{~K}^{-1} \cdot{ }^{7-10} \mathrm{Ker}$ so mehanske lastnosti celuloznih nanofibril primerljive z lastnostmi drugih inženirskih materialov (steklena, aramidna, kevlar vlakna), ${ }^{5}$ so primerna ojačitvena sredstva za utrjevanje najrazličnejših polimernih osnov.

Priprava biopolimernih nanokompozitov, osnovanih na celuloznih nanofibrilah ali nanokristalih temelji na vlivanju organske raztopine in nadaljnji evaporaciji topila ${ }^{11}$ ali na metodi ekstruzijskega mešanja, pri kateri mora biti ojačitveni element $\mathrm{v}$ obliki suhe snovi - navadno prahu. ${ }^{12} \mathrm{~V}$ prvem primeru pridobimo transparentne filmske strukture $\mathrm{z}$ navadno izboljšanimi bariernimi in mehanskimi lastnostmi. ${ }^{11,13}$ Možnosti uporabe nanokompozitov, izdelanih po drugem postopku predelave so precej bolj raznolike, ker jih je mogoče oblikovati v najrazličnejše profile oziroma končne izdelke. Po drugi strani je izdelava nanokompozitov s tehnologijo ekstruzije veliko bolj zapletena kot pri tehnologiji vlivanja in trenutno predstavlja številne izzive na raziskovalnem področju. Znanstvenih študij, v katerih bi bila opisana uspešna študija s področja ekstrudiranja celuloznih bionanokompozitov, je relativno malo. ${ }^{12,14-17}$ Pri ekstruzijskem postopku se soočamo s problematiko nehomogene porazdelitve ojačitvene faze po polimerni osnovi, kar poslabša kakovost in trajnost nastalih materialov. ${ }^{12-17}$ Pomembno omejitev uporabe NFC v takšnih sistemih predstavlja medij shranjevanja, ki je voda, in hidrofilna površina NFC, zaradi katere jo težko dispergiramo v medijih nepolarnega značaja. ${ }^{5}$ Mešanje NFC in polimerov različnega izvora je zato $\mathrm{v}$ večini primerov omejeno na vodna ali polarna okolja, ${ }^{17}$ tehnologije predelave pa na laboratorijsko merilo. ${ }^{13-14} \mathrm{Z}$ namenom izdelave bionanokompozitov ojačanih z NFC v industrijskem merilu, smo pripravo kompozitnih mešanic prilagodili ekstruzijskemu mešanju liofiliziranih koncentratnih mešanic PHB prahu in celuloznih nanofibril ter nadaljnji predelavi s tehnologijo brizganja. Predelovalne, morfološke in mehanske lastnosti nanokompozitnih materialov smo ovrednotili v odvisnosti od različnih utežnih razmerij NFC.

\section{MATERIALI IN METODE}

\subsection{Nanofibrilirana celuloza (NFC)}

Vodna suspenzija celuloznih nanofibril (1.6 utežnih $\%$ ) je bila pridobljena iz CBBP (Centre for Biocomposite and Biomaterial Processing), Univerza v Torontu, Kanada. Po podatkih proizvajalca je povprečni premer fibril med $25 \mathrm{~nm}$ in $70 \mathrm{~nm}$, njihova dolžina pa presega velikostno območje 1 mikrometra. Končni produkt je bil izdelan z večkrat ponovljenimi postopki fibrilacije beljenih celuloznih vlaken lesa iglavcev. Po kemični sestavi NFC vsebuje $91 \%$ celuloze, 8,7\% hemiceluloze in manj kot $0,3 \%$ lignina.

\subsection{Poli(3-hidroksibutirat) (PHB)}

$\mathrm{V}$ raziskavo smo vključili dve različni obliki poli(3-hidroksibutirata): prva v obliki granul pod tržnim imenom Biomer ${ }^{\circledR} \mathrm{P} 226$, druga pa $\mathrm{v}$ obliki prahu kot izhodni produkt bakterijsko vodenih fermentacijskih postopkov. Oba materiala sta bila pridobljena iz podjetja Biomer ${ }^{\circledR}$ biopolyesters, Krailling, Nemčija. Po podatkih proizvajalca, granulirana oblika PHB, Biomer®226, lahko vsebuje do 20 utežnih \% različnih aditivnih sredstev za stabilizacijo končnega produkta, katerih identiteta ni javno dostopna.

\subsection{Priprava PHB/NFC nanokompozitov}

Nanokompozite $\mathrm{z}$ utežnim deležem NFC v višini $(2$, $4,6,8$ in 10) \%, smo pripravili na osnovi PHB/NFC koncentratov in granulirane oblike biopolimerne osnove, $\mathrm{PHB}^{\circledR} \mathrm{P} 226$. Za pripravo koncentratnih mešanic ali "masterbach" komponent smo uporabili PHB v obliki prahu in NFC v vodni suspenziji. Biopolimerni prah, dispergiran $\mathrm{v}$ destilirani vodi, smo mešali $\mathrm{z}$ vodno suspenzijo nanofibril v utežnem razmerju 85/15. Pripravljen disperzni sistem smo zamrznili v tekočem dušiku in ga sušili $72 \mathrm{~h} \mathrm{~s}$ postopkom liofilizacije (LyoQuest freeze dryer, Telstar) pri tlačnih pogojih 0,040 mbar, temperaturi pladnjev $-22{ }^{\circ} \mathrm{C}$ in temperaturi kondenzatorja $-50{ }^{\circ} \mathrm{C}$. Sušen koncentrat smo nato ekstrudirali z dvopolžnim laboratorijskim ekstruderjem HAAKE $^{\text {TM }}$ MiniLab II (Thermo Scientific) pri delovni temperaturi $180{ }^{\circ} \mathrm{C}$ in hitrostjo vrtenja polžev 40 obratov/min. Ekstruzijsko predelane materiale smo nato granulirali in jih mešali s komponento $\mathrm{PHB}{ }^{\circledR} \mathrm{P} 226$. Pripravili smo pet različnih sestav kompozitnega materiala $\mathrm{v}$ odvisnosti od dodatka ojačitvene komponente NFC (Tabela 1). Za referenčni vzorec smo pripravili mešanico ekstrudiranega prahu $\mathrm{PHB}$ in granulirane komponente $\mathrm{PHB}^{\circledR} \mathrm{P} 226$ v utežnem razmerju 15/85. Kompozitne mešanice $\mathrm{PHB} / \mathrm{NFC} / \mathrm{PHB}^{\circledR} \mathrm{P} 226$ smo sušili $15 \mathrm{~h} \mathrm{v}$ laboratorijskem sušilniku pri $80{ }^{\circ} \mathrm{C}$, nato pa jih ekstrudirali pri delovni temperaturi $180^{\circ} \mathrm{C}$, zadrževalnim časom taline $10 \mathrm{~min}$ ter hitrostjo vrtenja polžev 40 obratov/min. Talino predelanega materiala smo brizgali s povezano enoto HAAKE ${ }^{\mathrm{TM}}$ MiniJet v standardno orodje za izdelavo nateznih preizkušancev tipa 1BA. Temperaturo brizganja smo nastavili na $185{ }^{\circ} \mathrm{C}$, temperaturo orodja na $45^{\circ} \mathrm{C}$, tlak brizganja je bil $500 \mathrm{~b}$, čas cikla in čas ohlajevanja pa $5 \mathrm{~s}$ oziroma $10 \mathrm{~s}$. Izdelane preizkušance smo 7 dni klimatizirali pri $23{ }^{\circ} \mathrm{C}$ in $50 \%$ vlažnosti, kot določa standard ISO 527-2. 
V. ŽEPIČ et al.: VPLIV DODATKA NANOFIBRILIRANE CELULOZE NA MEHANSKE LASTNOSTI ...

Tabela 1: Končna sestava PHB®P226/PHB mešanic glede na dodani utežni delež NFC

Table 1: Final compositions of $\mathrm{PHB}{ }^{\circledR} \mathrm{P} 226 / \mathrm{PHB}$ blends with respect to the weight ratio of NFC

\begin{tabular}{|c|c|c|c|c|}
\hline Oznaka vzorca & PHB & NFC & PHB®P226 & $\begin{array}{l}\text { Razmerje } \\
\text { komponent }\end{array}$ \\
\hline $\mathrm{PHB} / \mathrm{PHB}^{\circledR} \mathrm{P} 226$ & $1,35 \mathrm{~g}$ & - & $7,65 \mathrm{~g}$ & $15 / 85$ \\
\hline $\begin{array}{c}\mathrm{PHB} / \mathrm{NFC/} \\
\mathrm{PHB}^{\circledR} \mathrm{P} 226 \_2\end{array}$ & $1,17 \mathrm{~g}$ & $0,18 \mathrm{~g}$ & $7,65 \mathrm{~g}$ & $13 / 2 / 85$ \\
\hline $\begin{array}{c}\mathrm{PHB} / \mathrm{NFC} / \\
\mathrm{PHB}^{\circledR} \mathrm{P} 226 \_4\end{array}$ & $0,99 \mathrm{~g}$ & $0,36 \mathrm{~g}$ & $7,65 \mathrm{~g}$ & $11 / 4 / 85$ \\
\hline $\begin{array}{c}\mathrm{PHB} / \mathrm{NFC} / \\
\mathrm{PHB}^{\circledR} \mathrm{P} 226 \_6\end{array}$ & $0,81 \mathrm{~g}$ & $0,54 \mathrm{~g}$ & $7,65 \mathrm{~g}$ & $9 / 6 / 85$ \\
\hline $\begin{array}{c}\mathrm{PHB} / \mathrm{NFC/} \\
\mathrm{PHB}^{\circledR} \mathrm{P} 226 \_8\end{array}$ & $0,63 \mathrm{~g}$ & $0,72 \mathrm{~g}$ & $7,65 \mathrm{~g}$ & $7 / 8 / 85$ \\
\hline $\begin{array}{c}\mathrm{PHB} / \mathrm{NFC} / \\
\mathrm{PHB}^{\circledR} \mathrm{P} 226 \_10\end{array}$ & $0,45 \mathrm{~g}$ & $0,90 \mathrm{~g}$ & $7,65 \mathrm{~g}$ & $5 / 10 / 85$ \\
\hline
\end{tabular}

\subsection{Elektronska vrstična mikroskopija z delovanjem na poljsko emisijo (FE-SEM)}

Morfološke lastnosti nanokompozitnih komponent, NFC in PHB, smo opisali s pomočjo FE-SEM mikroskopa (Zeiss ULTRA plus, Nemčija) pri različnih povečavah. Pospeševalne napetosti (EHT) so variirale v območju od $1 \mathrm{kV}$ do $3 \mathrm{kV}$, razdalja snemanja je bila med $3 \mathrm{~mm}$ in $3.5 \mathrm{~mm}$ Vsi testni vzorci so bili prevlečeni s tanko plastjo ogljika s pomočjo naparjevalne naprave BAL - TEC/SCD 500.

\subsection{Mehanske lastnosti nanokompozitnih sistemov}

Mehanske lastnosti referenčnega vzorca in nanokompozitov z različnimi utežnimi dodatki NFC so bile določene preko nateznega preizkusa na trgalnem stroju Zwick/Roell Z005. Natezni modul $\left(E_{\mathrm{t}}\right)$, trdnost $\left(\sigma_{\mathrm{M}}\right)$ in raztezek pri pretrgu $\left(\varepsilon_{\mathrm{b}}\right)$ je bil za preiskane materiale določen na $30 \mathrm{~mm}$ razdalji med čeljustmi, pri hitrosti obremenjevanja $5 \mathrm{~mm} / \mathrm{min}$. Za vsako končno sestavo je bilo testiranih najmanj pet preizkušancev.

\section{REZULTATI Z RAZPRAVO}

\subsection{Ekstruzijsko mešanje nanokompozitnih zmesi in predelava s tehnologijo brizganja}

Ko smo dispergirali PHB prah v vodni suspenziji celuloznih nanofibril, je nastala stabilna zmes (Slika 1). Po sušenju te mešanice z zamrzovanjem (liofilizacijo) so nastali lahki, porozni in krhki kosmi (Slika 1). Tehnološka predelava takega materiala je zahtevna, predvsem zaradi velike prostornine sušenega produkta in njegove občutljivosti na vlago. Pri procesu ekstruzijskega mešanja smo z izklopom funkcije zadrževalnega časa, $\mathrm{z}$ izbiro ročnega doziranja ter visokimi obrati vrtenja polžev, pretok taline vodili kontinuirano, pri čemer je bila poraba operativne energije stroja nižja, temperaturna degradacija materiala pa zaradi kratkega zadrževalnega časa izključena. Ekstrudat v obliki traku (Slika 1) smo v nadaljnjih postopkih predelave granulirali in ga uporabili
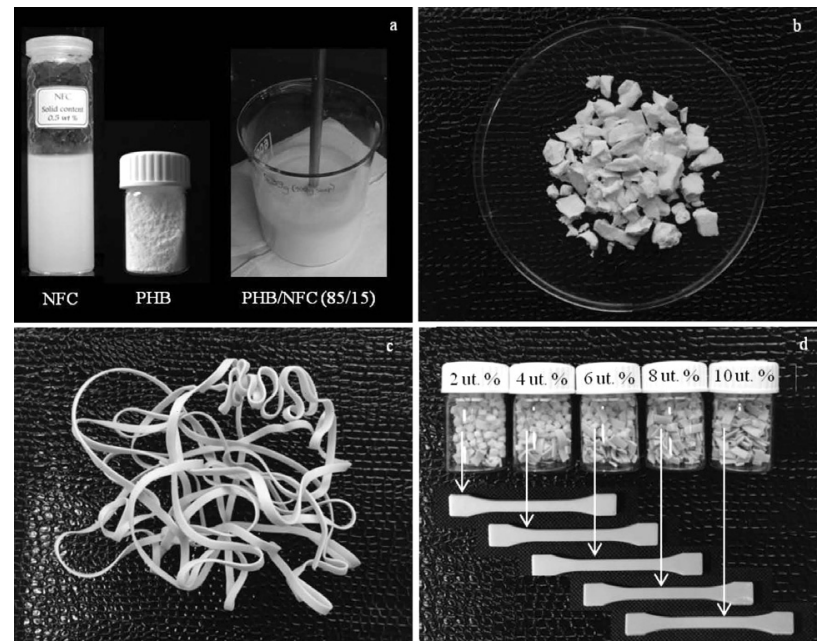

Slika 1: Priprava nanokompozitnih mešanic: a) sestavne komponente masterbatch sistemov: vodna suspenzija NFC, PHB v obliki prahu in disperzni sistem $\mathrm{PHB} / \mathrm{NFC}$, b) liofiliziran produkt $\mathrm{PHB} / \mathrm{NFC}$, c) ekstrudat liofilizirane mešanice $\mathrm{PHB} / \mathrm{NFC}$ in d) nanokompozitne mešanice $\mathrm{PHB} / \mathrm{NFC} / \mathrm{PHB}{ }^{\mathrm{P}} \mathrm{P} 226$ in brizgani testni preizkušanci $\mathrm{z}$ različnim vsebnostnim deležem NFC

Figure 1: Preparation of the nanocomposite blends: a) constituent components of the masterbatch blends: an aqueous suspension of NFC, PHB in the powder form and a dispersed aqueous system of $\mathrm{PHB} / \mathrm{NFC}$, b) freeze-dried product of $\mathrm{PHB} / \mathrm{NFC}$, c) extrudate of the lyophilized $\mathrm{PHB} / \mathrm{NFC}$ blend, d) nanocomposite blends of $\mathrm{PHB} / \mathrm{NFC}$ / PHB®P226 and injection-moulded test specimens with various contents of NFC

kot dodatek granulirani obliki PHB (PHB $\left.{ }^{\circledR} \mathrm{P} 226\right)$. Pri iterativni predelavi večkomponentnih sestav je za homogeno porazdelitev materialnih komponent potrebno zagotoviti dovolj dolg obratovalni čas ekstruzijskega mešanja. Ob upoštevanju združevanja treh različnih materialnih komponent, t.im. PHB, NFC in $\mathrm{PHB}^{\circledR} \mathrm{P} 226$, ter želji po enakomerni porazdelitvi nanofibril, je bil čas cikličnega ekstruzijskega mešanja podaljšan na $10 \mathrm{~min}$. Z ozirom na kakovost površine izhodnih brizganih produktov (Slika 1) smo ugotovili, da mora biti temperatura orodja sorazmerno visoka, četudi se cikel predelave s tem časovno podaljša.

\subsection{Morfološka analiza nanokompozitnih komponent}

Morfološka preiskava nanofibrilirane celuloze $\mathrm{v}$ vodni suspenziji in njene sušene različice, pridobljene $s$ postopkom liofilizacije, kaže na nekatere pomembne razlike $\mathrm{v}$ površinski strukturi fibrilarnih entitet. Pri izvorni obliki NFC so razvidne dolge in tanke fibrile $\mathrm{s}$ povprečnimi premeri od $20 \mathrm{~nm}$ do $60 \mathrm{~nm}$ (Slika 2), medtem ko je morfološka površina sušenega vzorca sestavljena iz plastno urejenih fibril, ki se prepletajo $\mathrm{v}$ obliki širših pramenov in ustvarjajo videz zamrežene površine (Slika 2). Njihove prečne dimenzije so relativno velike $(1,2 \mu \mathrm{m})$, dosegajo pa tudi sub-mikronske $(35 \mathrm{~nm})$ vrednosti. Povečane premere celuloznih nanofibril v suhem stanju je mogoče pripisati tvorbi dodatnih vodikovih vezi med postopkom liofilizacije, ${ }^{18-20} \mathrm{ki}$ se pojavi selektivno med stično razporejenimi fibrilami. ${ }^{21}$ 
V. ŽEPIČ et al.: VPLIV DODATKA NANOFIBRILIRANE CELULOZE NA MEHANSKE LASTNOSTI ...
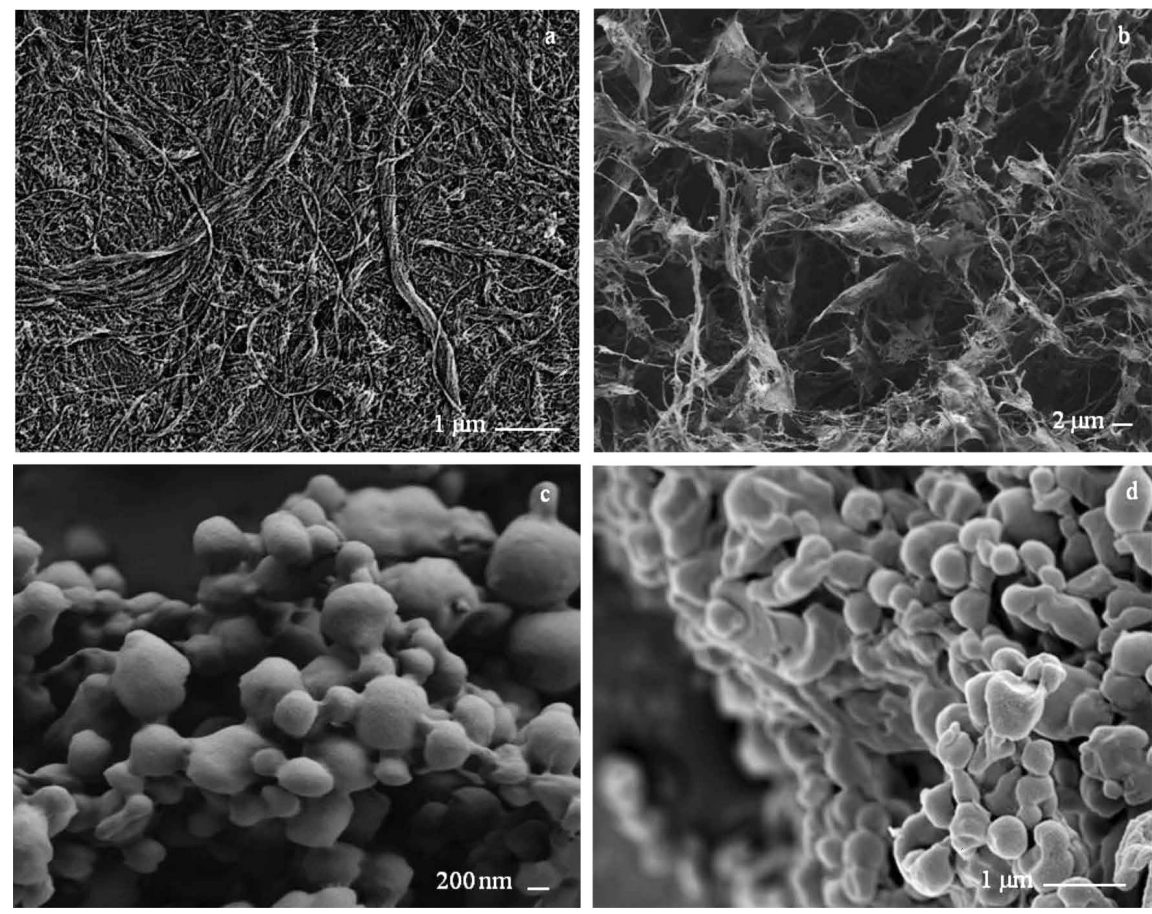

Slika 2: Nanokompozitne komponente: a) vodna suspenzija NFC, b) sušena oblika NFC, pridobljena s postopkom liofilizacije, c) PHB v obliki prahu in d) liofiliziran produkt PHB prahu dispergiranega $\mathrm{v}$ vodnem mediju

Figure 2: Nanocomposite components: a) NFC aqueous suspension, b) freeze-dried NFC, c) PHB in the powder form, d) freeze-dried product of the PHB powder dispersed in an aqueous medium

Fenomen nanofibrilarne agregacije, ki je posledica intrain intermolekularne tvorbe vodikovih vezi, opisujemo $\mathrm{z}$ izrazom hornifikacija. ${ }^{18}$

Morfologija PHB prahu predstavlja delce skoraj pravilnih sferičnih oblik, povprečne velikosti $0,5 \mu \mathrm{m}$ (Slika 2). Sprememba v morfologiji površine liofiliziranega PHB vzorca je zanemarljiva (Slika 2), opazna je le nekoliko bolj sprijeta sestava sferičnih polimernih struktur.

Mešanica PHB/NFC v utežnem razmerju 85/15, ki smo jo pridobili po sušenju z zamrzovanjem je prikazana na Sliki 3 pri različnih mikroskopskih povečavah. Sušena oblika koncentrirane mešanice sestoji iz sferičnih delcev polimera, ujetih $\mathrm{v}$ mreži prepletenih nanofibril $\mathrm{s}$ povprečnimi prečnimi dimenzijami $69 \pm 14 \mathrm{~nm}$. Te so v večini individualno razporejene po polimerni osnovi, na nekaterih mestih pa ostajajo v agregirani obliki zaradi pojava hornifikacije, ki nastopi med postopkom sušenja.

\subsection{Mehanske lastnosti nanokompozitnih vzorcev}

Vpliv dodatka $\mathrm{PHB} / \mathrm{NFC} \mathrm{v}$ različnih utežnih razmerjih na mehanske lastnosti matrične osnove $\mathrm{PHB}^{\circledR} \mathrm{P} 226$ smo določili na osnovi nateznega preizkusa in primerjali $\mathrm{z}$ vrednostmi mehanskih parametrov $\left(E_{\mathrm{t}}, \sigma_{\mathrm{M}}\right.$ in $\left.\varepsilon_{\mathrm{b}}\right)$ referenčnega vzorca $\mathrm{PHB} / \mathrm{PHB}^{\circledR} \mathrm{P} 226$. Reprezentativne krivulje preiskovanih materialov so v odvisnosti od napetosti $(\sigma)$ in raztega $(\varepsilon)$ prikazane na Sliki 4 , povprečne vrednosti mehanskih parametrov s standardno deviacijo pa so zbrane v Tabeli 2.
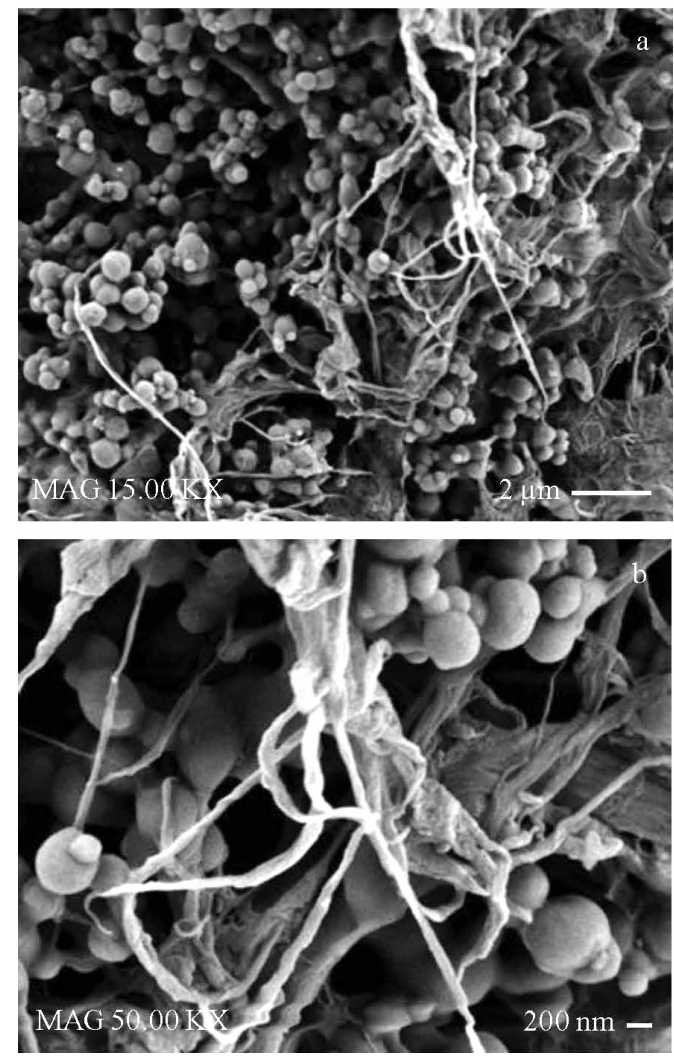

Slika 3: Koncentrirane mešanice $\mathrm{PHB} / \mathrm{NFC}$ (85/15): a) pri 15.000 -kratni mikroskopski povečavi in b) pri 50.000-kratni mikroskopski povečavi

Figure 3: PHB/NFC masterbatch mixtures (85/15): a) 15.000×, b) $50.000 \times$ magnification 
Tabela 2: Mehanske lastnosti kompozitnih vzorcev glede na dodani utežni delež NFC

Table 2: Mechanical properties of the resulting composites with various contents of NFC

\begin{tabular}{|c|c|c|c|}
\hline \multirow{2}{*}{ Vzorec } & $\begin{array}{c}\text { Natezni modul } \\
\left(E_{\mathrm{t}}\right)\end{array}$ & $\begin{array}{c}\text { Natezna } \\
\text { trdnost }\left(\sigma_{\mathrm{M}}\right)\end{array}$ & $\begin{array}{l}\text { Raztezek pri } \\
\text { pretrgu }\left(\varepsilon_{\mathrm{b}}\right)\end{array}$ \\
\hline & $\mathrm{MPa}$ & $\mathrm{MPa}$ & $\%$ \\
\hline $\begin{array}{l}\mathrm{PHB} / \mathrm{NFC} / \\
\mathrm{PHB}^{\circledR} \mathrm{P} 226\end{array}$ & $1340 \pm 90$ & $20 \pm 1$ & $2,4 \pm 1,0$ \\
\hline $\begin{array}{c}\mathrm{PHB} / \mathrm{NFC} / \\
\mathrm{PHB}^{\circledR} \mathrm{P} 226 \_2\end{array}$ & $1330 \pm 30$ & $22 \pm 1$ & $3,3 \pm 0,2$ \\
\hline $\begin{array}{c}\mathrm{PHB} / \mathrm{NFC} / \\
\mathrm{PHB}^{\circledR} \mathrm{P} 226 \_4\end{array}$ & $1380 \pm 30$ & $22 \pm 0,4$ & $3,4 \pm 0,3$ \\
\hline $\begin{array}{c}\mathrm{PHB} / \mathrm{NFCl} \\
\mathrm{PHB}^{\circledR} \mathrm{P} 226 \_6\end{array}$ & $1470 \pm 20$ & $23 \pm 1$ & $3,1 \pm 0,2$ \\
\hline $\begin{array}{c}\mathrm{PHB} / \mathrm{NFC} / \\
\mathrm{PHB}^{\circledR} \mathrm{P} 226 \_8\end{array}$ & $1520 \pm 50$ & $24 \pm 0,4$ & $3,1 \pm 0,3$ \\
\hline $\begin{array}{c}\text { PHB/NFC/ } \\
\text { PHB }^{\circledR} \text { P226_10 }\end{array}$ & $1720 \pm 40$ & $26 \pm 1$ & $3,1 \pm 0,5$ \\
\hline
\end{tabular}

Glede na potek $\sigma-\varepsilon$ krivulj preiskanih vzorcev je razvidno, da dodatek NFC v splošnem izboljša mehanske lastnosti referenčnega vzorca $\mathrm{PHB} / \mathrm{PHB}^{\circledR} \mathrm{P} 226$, stopnja opisane spremembe pa je odvisna od utežnega razmerja ojačitvene komponente (Slika 4). Višji je utežni delež NFC v končni sestavi vzorca, višji so parametri elastične deformacije $\left(E_{\mathrm{t}}\right)$, trdnosti $\left(\sigma_{\mathrm{M}}\right)$ in raztezka $\left(\varepsilon_{\mathrm{b}}\right)$ nanokompozitnih materialov. Dodatek NFC v višini $2 \%$ in $4 \%$ vpliva na rahlo povišanje elastičnega modula (iz $1340 \mathrm{MPa}$ na $1380 \mathrm{MPa}$ ) in natezne trdnosti (iz $20 \mathrm{MPa}$ na približno $22 \mathrm{MPa}$ ), medtem ko so spremembe $\mathrm{v}$ vrednostih raztezka pri pretrgu bistveno bolj izrazite saj se $\mathrm{z}$ dodatkom celuloznih nanofibril $\mathrm{v}$ višini 10 utežnih \% izboljša za skoraj $40 \%$. Ob povišanih deležih NFC elastični modul in natezna trdnost nanokompozitnih vzorcev naraščata (Preglednica 2), vrednosti za raztezek pri pretrgu pa se postopoma znižujejo, vendar še vedno ostajajo nad izmerjenimi vrednostmi za referenčni vzo-

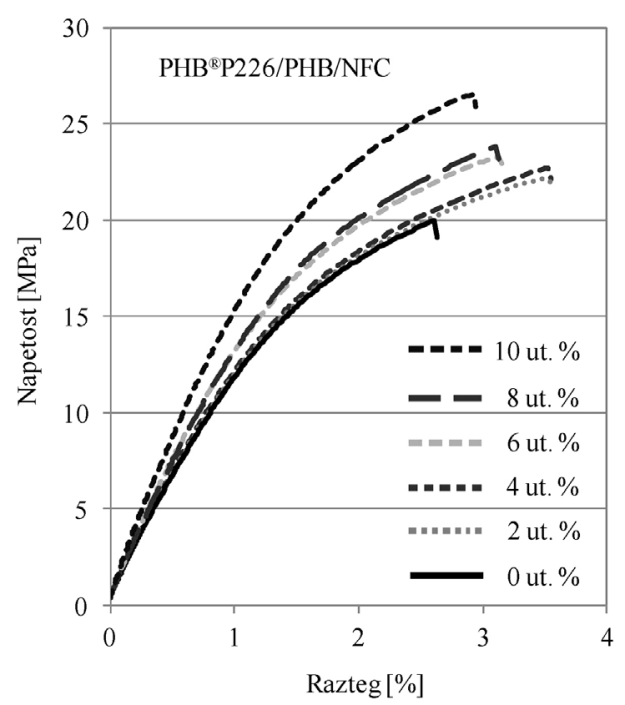

Slika 4: Krivulje odnosa napetost-raztezek kompozitnih vzorcev glede na variabilni utežni delež NFC

Figure 4: Stress-strain curves of the resulting composites with various contents of NFC rec. Najvišje vrednosti izmerjenih mehanskih parametrov smo zabeležili pri nanokompozitih z dodanim deležem ojačitve v višini $10 \%$, pri čemer se modul elastičnosti in natezna trdnost zvišata za približno $28,5 \%$ in $30 \%$, raztezek pri pretrgu pa za $28 \%$.

Glede na izsledke dosedanjih znanstvenih študij o spajanju tovrstnih materialov je navedba take izboljšave mehanskih lastnosti izjemno redka. Navadno izboljšan modul elastičnosti in večjo natezno trdnost spremlja manjši pretržni raztezek, ${ }^{12,14-16} \mathrm{kar}$ prispeva $\mathrm{k}$ povečani krhkosti izhodnih materialov. Delno izboljšanje ali celo poslabšanje mehanskih lastnosti nanokompozitnih formulacij z dodano komponento NFC se največkrat pripisuje njeni težnji k agregaciji med postopkom ekstruzijskega mešanja in nehomogeni porazdelitvi ojačitvene faze po polimerni osnovi. ${ }^{12-16,19}$ Rezultati mehanske analize nanokompozitov izdelanih $\mathrm{v}$ tej študiji, pa $\mathrm{v}$ nasprotju s temi trditvami kažejo, da dodatek celuloznih nanofibril v obliki liofiliziranega koncentrata vodi do pridobitve ne le trdnih in togih, ampak tudi žilavih materialov. Mehanske lastnosti nanokompozitnih sistemov so odvisne od združljivosti medfaznih komponent, porazdelitve ojačitvene faze in njene morfološke oblike. Sklepamo, da s predhodnim postopkom mešanja polimernega prahu in nanofibril v vodnem mediju dosežemo koloidno stabilnost disperznega sistema in homogeno porazdelitev nanofibril po polimerni osnovi. Ta se glede na rezultate morfološke preiskave vzorcev ohrani skozi postopek liofilizacije in nadaljnjo ekstruzijsko pripravo nanokompozitov ter pomembno vpliva na izboljšanje mehanskih lastnosti izhodnih produktov.

\section{SKLEPNE UGOTOVITVE}

$\mathrm{V}$ prispevku je podan inovativni postopek izdelave nanokompozitov na osnovi koncentrirane mešanice biopolimernega prahu in celuloznih nanofibril z visokim utežnim deležem. Ker je opisana tehnologija prenosljiva na industrijski predelovalni obrat je še posebno zanimiva $\mathrm{z}$ vidika tržno usmerjenih aplikacij za tovrstne materiale in širjenja njihovih proizvodnih kapacitet. Z optimizacijo priprave koncentratnih nanokompozitnih mešanic in ustreznim utežnim deležem NFC v končni materialni formulaciji smo dokazali, da je z izbrano metodo tehnološke predelave ekstruzije in brizganja mogoče izdelati trdne, toge in žilave materiale, pri čemer delež ojačitvene faze narekuje stopnjo izboljšave mehanskih lastnosti biopolimerne osnove. Višji je delež dodanih celuloznih nanofibril v končni sestavi vzorca, višje so izmerjene vrednosti mehanskih parametrov. V primerjavi z referenčnim vzorcem imajo nanokompoziti z dodatkom 10 utežnih \% NFC za okoli $30 \%$ višji modul elastičnosti in prenesejo za približno $6 \mathrm{MPa}$ višjo pretržno napetost. Pri vseh nanokompozitih smo zabeležili tudi pomembno višje vrednosti raztezka pri pretrgu, torej lahko sklepamo, da je adhezivni spoj med matrično in ojačitveno fazo dosežen, porazdelitev nanofibril pa homogena, kar 


\section{V. ŽEPIČ et al.: VPLIV DODATKA NANOFIBRILIRANE CELULOZE NA MEHANSKE LASTNOSTI ...}

potrjujejo tudi mikroskopske preiskave nanokompozitnih mešanic.

PHB kompoziti ojačani z naravnimi vlakni kot so bambusova, ${ }^{22}$ lesna ali kenaf vlakna ${ }^{23}$ beležijo bistveno nižje vrednosti natezne trdnosti in raztezka pri pretrgu kot jih izkazujejo nanokompoziti izdelani v tej študiji. Natezno trdnost PHB kompozitov ojačanih z bambusovimi vlakni ${ }^{22}$ je mogoče preseči za dvakratno vrednost že pri zelo nizkih utežnih deležih NFC (2 utežna \%), medtem ko se raztezne lastnosti PHB osnove z dodatkom celuloznih nanofibril izboljšajo za več kot $400 \% \mathrm{v}$ primerjavi z dobljenimi vrednostmi raztezka za PHB kompozite na osnovi naravnih vlaken. ${ }^{22,23} \mathrm{Z}$ izdelavo nanokompozitov na osnovi liofiliziranih koncentratnih mešanic PHB/NFC smo dokazali, da lahko izhodni produkti dosegajo izboljšane mehanske lastnosti že ob zelo nizkem utežnem dodatku nano ojačitvenega elementa in tako predstavljajo zanimivo alternativo konvencionalnim mikro- ali makrobiokompozitnim materialom ter sintetičnim polimerom s steklenimi ali karbonsko osnovanimi polnili.

\section{ZAHVALA}

Avtorji se zahvaljujejo Javni agenciji za raziskovalno dejavnost Republike Slovenije za finančno podporo v okviru programske skupine P4-0015. Zahvala gre prav tako Agenciji SPIRIT Slovenija za delno finančno podporo v okviru Evropskega socialnega sklada Evropske Unije, v okviru katere je nastal del te raziskave.

\section{LITERATURA}

${ }^{1}$ D. Garlotta, A literature Review of Poly(Lactic Acid), Journal of Polymers and the Environment, 9 (2001) 63-84, doi:10.1023/ A: 1020200822435

${ }^{2}$ P. M. Visakh, Polyhydroxyalkanoates (PHAs), their Blends, Composites and Nanocomposites: State of the Art, New Challenges and Opportunities, Polyhydroxyalkanoate (PHA) Based Blends, Composites and Nanocomposites, (2014) 1-17, doi:10.1039/ 9781782622314-00001

${ }^{3}$ K. Van de Velde, P. Kiekens, Biopolymers: overview of several properties and consequences on their applications, Polymer Testing, 21 (2002), 433-442, doi:10.1016/S0142-9418(01)00107-6

${ }^{4}$ C. Winkworth-Smith, T. J. Foster, General Overview of Biopolymers: Structure, Properties, and Applications, Handbook of Biopolymer-Based Materials: From Blends and Composites to Gels and Complex Networks (eds S. Thomas, D. Durand, C. Chassenieux and P. Jyotishkumar), 2013, Wiley-VCH Verlag GmbH \& Co. KGaA, Weinheim, Germany, doi:10.1002/9783527652457.ch2

${ }^{5}$ S. J. Eichhorn, A. Dufresne, M. Aranguren, N. E. Marcovich, J. R. Capadona, S. J. Rowa, C. Weder, W. Thielemans, M. Roman, S. Renneckar, W. Gindl, S. Veigel, J. Keckes, H. Yano, K. Abe, M. Nogi, A. N. Nakagaito, A. Mangalam, J. Simonsen, A. S. Benight, A. Bismarck, L. A. Berglund, T. Peijs, Review: current international research into cellulose nanofibres and nanocomposites, Journal of Material Science, 45 (2010) 1, 1-33, doi:10.1007/s10853-0093874-0

${ }^{6}$ W. J. Orts, J. Shey, S. H. Imam, G. M. Glenn, M. E. Guttman, J. F. Revol, Application of cellulose microfibrils in polymer nanocom- posites, Journal of Polymers and the Environment, 13 (2005) 4, 301-306, doi:10.1007/s10924-005-5514-3

${ }^{7}$ K. Tashiro, M. Kobayashi, Theoretical evaluation of three-dimensional elastic contacts of native and regenerated celluloses: role of hydrogen bonds, Polymer, 32 (1991), 1516-1526, doi:10.1016/ 0032-3861(91)90435-L

${ }^{8}$ S. J. Eichhorn, R. J. Young, The Young's modulus of a microcrystalline cellulose, Cellulose, 8 (2003), 197-207, doi:10.1023/ A: 1013181804540

${ }^{9}$ A. Šturcova, G. R. Davies, S. J. Eichorn, Elastic modulus of stresstransfer properties of tunicate cellulose whiskers, Biomacromolecules, 6 (2005), 1055-1061, doi:10.1021/bm049291k

${ }^{10} \mathrm{~S}$. Iwamoto, W. Kai, A. Isogai, T. Iwata, Elastic modulus of single cellulose microfibrils from tunicate measured by atomic force microscopy, Biomacromolecules, 10 (2009), 2571-2576, doi:10.1021/ bm900520n

${ }^{11}$ M. Sanchez-Garcia, J. M. Lagaron, On the use of plant cellulose nanowhiskers to enhance the barrier properties of polylactic acid, Cellulose, 17 (2010), 987-1004, doi:10.1007/s10570-010-9430-x

${ }^{12}$ K. Oksman, A. P. Mathew, D. Bondeson, I. Kvien, Manufacturing process of cellulose whiskers/polylactic acid nanocomposites, Composite Science Technology, 66 (2006), 2776-2784, doi:10.1016/ j.compscitech.2006.03.002

${ }^{13}$ M. Bulota, K. Kreitsmann, M. Hughes, J. Paltakari, Acetylated microfibrillated cellulose as a toughening agent in poly(lactic acid), J App Polym Sci, 126 (2012), 448-457, doi:10.1002/app.36787

${ }^{14}$ M. Jonoobi, A. P. Mathew, M. M. Abdi, M. Davoodi Makinejad, K. Oksman, A comparison of modified and unmodified cellulose nanofiber reinforced polylactic acid (PLA) prepared by twin screw extrusion, Polymer Environment, 20 (2012), 991-997, doi:10.1007/ s10924-012-0503-9

${ }^{15}$ Y. Srithep, T. Ellingham, J. Peng, R. Sabo, C. Clemons, L. S. Turng, S. Pilla, Melt compounding of poly(3-hydroxybutyrate-co-3-hydroxyvalerate)/nanofibrillated cellulose nanocomposites, Polymer Degradation and Stability, 98 (2013), 1439-1449, doi:10.1016/ j.polymdegradstab.2013.05.006

${ }^{16}$ M. Jonoobi, J. Harun, A. P. Mathew, K. Oksman, Mechanical properties of cellulose nano-fiber (CNF) prepared by twin screw extrusion, Composite Science and Technology, 70 (2010), 1742-1747, doi:10.1016/j.compscitech.2010.07.005

${ }^{17}$ G. Siqueira, J. Bras, A. Dufresne, Cellulosic bionanocomposites: A review of Preparation, Properties and Applications, Polymer, 2 (2010), 728-765, doi:10.3390/polym 2040728

${ }^{18}$ A. M. Scallan, The structure of the cell wall of wood - A consequence of anisotropic inter-microfibrillar bonding, Wood Science, 6 (1974) 3, 226-271

${ }^{19}$ V. Žepič, I. Poljanšek, P. Oven, M. Čop, COST-FP1105: Properties of PLA films reinforced with unmodified and acetylated freeze dried nanofibrillated cellulose Holzforschung, 70 (2016) 12, 1125-1134

${ }^{20}$ V. Žepič, I. Poljanšek, P. Oven, Š. A. Sever, A. Hančič, Effect of drying pretreatment on the acetylation of nanofibrillated cellulose, Bioresources, 10 (2015) 4, 8148-8167

${ }^{21}$ V. Žepič, E. Š. Fabjan, M. Kasunič, R. C. Korošec, A. Hančič, P. Oven, L. Perše, I. Poljanšek, Morphological, thermal, and structural aspects of dried and redispersed nanofibrillated cellulose (NFC), Holzforschung, 68 (2014) 6, 657-667, doi:10.1515/hf-2013-0132

${ }^{22}$ R. Krishnaprasad, N. R. Veena, H. J. Maria, R. Rajan, M. Skrifvars, K. Joseph, Mechanical and Thermal Properties of Bamboo Microfibril Reinforced Polyhydroxybutyrate Biocomposites, J Polym Environ, 17 (2009) 2, 109-114, doi:109. doi:10.1007/s10924-0090127-X

${ }^{23}$ S. Kuciel, A. Liber-Knec, Biocomposites based on PHB filled with wood or kenaf fibers, Polimery, 3 (2011), 218-223 